\title{
The Adjustment Factors: Its Validity on the Admissions Process of the University of the Philippines College of Medicine (UPCM)
}

\author{
Carlo G. Catabijan, MD, MAHPS \\ Department of Biochemistry and Molecular Biology, College of Medicine, University of the Philippines Manila
}

\begin{abstract}
Background. With the purpose of ensuring fairness and a level playing field in the selection process, the new admissions policy of the University of the Philippines College of Medicine (UPCM) has applied adjustment factors $(\mathrm{AF})$ in the computation of the general weighted averages (GWAs) of applicants.
\end{abstract}

Objective. The objective of the study was to the determine the validity of adjustment factors in ensuring fairness in recalibrating GWAs of applicants for admissions.

Methods. This study described the mean AF scores of the different pre-medical courses of lateral entrants as well as their historic academic performance such as the mean university predicted grades (UPG), UP College Admissions Test scores (UPCAT) and high school weighted averages (HSWA), National Medical Admissions Test (NMAT) scores, pre-medical general weighted average grades (PMGWAG) and Learning Unit 3 Medicine general weighted average grades (LU3 MGWAG). Correlative analysis was done using Pearson's correlation between the mean AF scores of the different pre-medical courses and their mean UPG, UPCAT and HSWA and LU3 MGWAG.

Results. The study showed that pre-medical courses from UP Manila obtained higher mean AF scores, while those from UP Diliman had better scholastic performance with higher mean UPG, UPCAT HSWA, NMAT, PMGWAG and LU3 MGWAG. Those who obtained a high score in the adjustment factors, namely BS Computer Science in UPM and BS Applied Physics in UPM, ranked lowest in the mean UPG, UPCAT, HSWA and low in NMAT, PMGWAG and LU3 MGWAG. The reverse was also true as those courses that ranked high in the mean UPG, UPCAT and HSWA, namely BS Molecular Biology and Biotechnology UPD, BS Psychology UPD and BS Biology UPD, acquired relatively low mean AF scores. Within statistical significance, inverse correlation was established between mean AF scores of the different pre-medical courses and mean UPG and UPCAT scores.

Conclusion. The study invalidated the use of AFs in the admissions process of UPCM. The AF did not guarantee fairness in the selection process, as it merely lowered down the GWAs of those who performed academically well in pre-medical courses. The current formula for the computation of AF is grounded on faulty assumption that high GWAs were all due to grade inflation. It is therefore recommended that implementation of the AF be immediately held in abeyance until its validity issues are resolved.

Keywords: Medical college admission, medical education, policy review

\section{INTRODUCTION}

In 2017, the University of the Philippines College of Medicine (UPCM) implemented a new admissions policy that was sanctioned and approved at all levels, from the College Council, University Council, up to the Board of Regents.

Corresponding author: Carlo G. Catabijan, MD, MAHPS Department of Biochemistry and Molecular Biology College of Medicine

University of the Philippines Manila

547 Pedro Gil Street, Ermita, Manila 1000, Philippines

Email: cdcatabijan@up.edu.ph
The new policy was officially promulgated in January 2017 for immediate implementation. ${ }^{1}$ The new admissions policy brought forth revisions and amendments to a three-decade old policy, included the derivation and the incorporation of 
an adjustment factor $(\mathrm{AF})$ in the computation of pre-medical general weighted average (GWA).

The formulation and utilization of an AF is an untested and a trailblazing amendment to the admissions policy of UPCM. In fact, it is a pioneering undertaking in the entire country's medical selection process. Incorporated in the computation of pre-medical GWA, the AF aims to level the playing field among the applicants, coming from a wide variety of pre-medical courses and academic institutions. As different baccalaureate courses, campus, colleges, and universities may have varying grading standards and levels of academic difficulties, stringencies, and leniencies, some adjustment measures must be applied to ensure fair comparability and standardization of grades (GWA).

Patterned after the derivation of the university predicted grade (UPG), ${ }^{2}$ the concept behind the AF is to recognize the differences among pre-medical courses in terms of grading standards and the ease or difficulty in getting good grades. It also addresses the problems of inequity related to grade inflation, which is a pervasive reality in the academic community. ${ }^{3-6}$

The utilization of AF stood to be the most contentious part of the new admissions policy as this was met with a lot of queries, negative feedback, and complaints from the very outset of its implementation. Reactions ranging from simple complaints and appeals to threats of protest confronted the admissions committee on its initial application of the AF. Given this context, this study reviewed the impact of the application of AF on the admissions landscape of UPCM. Likewise, this research dissected the formula and components of $\mathrm{AF}$ and correlated them with its observed impact. Lastly, this undertaking tested and determined the validity of the $\mathrm{AF}$.

\section{REVIEW OF LITERATURE}

The general weighted average (GWA), the overall summarization of a student's grades throughout a course, has been considered the most important parameter to evaluate academic achievement. This historical record may be the most indispensable factor in predicting student performance. However, raw or non-adjusted GWA score cannot be used in assessment of students' scholastic standing for admissions purposes as grades are not always comparable across all courses, departments, and instructors. In many educational settings, students may be prone to or enticed to take courses that are perceived to be easier and wherein high grades are less challenging to achieve. ${ }^{7}$ In such cases, the raw GWA would overstate the performance of a student who chooses a relatively easy course of study over another who chooses a more difficult course. ${ }^{8,9}$ Although GWA is still the most reliable indicator of previous academic performance, it is not a perfect predictor of performance and achievement of medical training..$^{10}$ Nevertheless, GWA remains the most common and predominant parameter in the selection process of medical schools as it still the most consistent independent predictor of success in the medical program. ${ }^{11,12}$

Since GWAs and grades represent the currency of education and perform an accountability function on several levels, grade inflation and a lack of precision in the grading process can have a profound and negative influence on higher education. ${ }^{13}$ Institutional grading standard, norms, biases ${ }^{14}$ and idiosyncrasies must be considered in processing GWAs to ensure comparability and fairness. Those who finished rigorous, difficult academic program/course with stringent grading policies, as they are disadvantaged, must be allotted certain credit in their GWA.

It is a common strategy among students who aim to enter highly competitive medical schools like UPCM to enroll into an "easy" pre-medical course to earn a higher GWA. Recent studies revealed that students who performed below par academically in medicine, graduated from courses that were known and popular to be relatively easy and gave generally higher grades. ${ }^{15}$ Thus, raw grades alone especially coming from different courses are difficult to compare and interpret, despite they are supposed to be numerical and "objective." They must be deciphered with circumspection as they gauge different and unstandardized levels of academic achievement and accomplishment of graduates from different courses and institutions.

In this context, standardization of GWAs is one of the many challenges that confront the selection process of medical institutions. With the goal of addressing this issue, methods of grade adjustment have been adopted by many institutions across the globe to make GWAs standardized and comparable (Table 1). ${ }^{16}$ The adjustment scheme ensures objective comparability of grades despite heterogeneity in pre-medical courses, schools, and grading standards.

A recent study validated the admissions criteria being utilized at UPCM, namely the pre-admission GWA and NMAT, as they were both proven to be predictive of medical students' academic performance in terms of grades in the medical school, class ranking and medical board rating. ${ }^{17}$ The validity of these predictors was further enhanced on simulated application of different AF on the pre-admissions GWA. ${ }^{18}$ Likewise, these AF made comparability of GWAs more reliable and consistent.

The grade adjustment method is not a novelty in the arena of academic program selection and admissions. Mainly utilized for the propose of improving the predictive validity of GWA, grade adjustment methods have been studied as early as 1913 by Starch and Elliot. ${ }^{19}$ From then on, several other methods, grounded on different statistical formula and assumptions, have been developed, tested, and validated.

The comprehensive review conducted by Young et al. on several grade adjustment methods used in collegiate admissions process through the past 27 years concluded that these grades adjustment methods made GPAs (Grade Point Average) more reliable and predictive of academic performance than the traditional unadjusted grades. Furthermore, 
The Validity of Adjustment Factors

Table 1. Grade adjustment methods

\begin{tabular}{|c|c|c|}
\hline Grade adjustment method & Institution(s) & Source \\
\hline Linear adjustment of undergraduate grades using LSAT college mean & 27 law schools & Boldt (1976) LSAC \\
\hline Equipercentile equating of grade scales of schools & 23 law schools & Braun \& Szatrowski (1984) JES \\
\hline Within-department and between-department linear adjustment index & Dartmouth & Elliott \& Strenta (1988) JEM \\
\hline Projected GPAs computed from admissions measures for $12-27$ major fields & $\begin{array}{l}\text { UC Davis, Irvine, Los } \\
\text { Angeles, and San Diego }\end{array}$ & Goldman \& Hewitt (1975) JEM \\
\hline Projected GPAs computed from admissions measures for 12 major fields & UC-Riverside & $\begin{array}{l}\text { Goldman, Schmidt, Hewitt, Fisher } \\
\text { (1974) AERJ }\end{array}$ \\
\hline Within-subjects pairwise comparisons of grades in 17 major fields & UC-Riverside & Goldman \& Widawski EPM (1976) \\
\hline Analysis of individual course grades in 88 introductory courses & San Diego State & McCornack \& McLeod (1988) JEM \\
\hline $\begin{array}{l}\text { Grades were compared using } 5 \text { measures of student aptitude and } \\
\text { course overlap }\end{array}$ & 38 colleges & Ramist, Lewis, \& McCamley (1990) CB \\
\hline Between-department additive adjustment index for 18 departments & Dartmouth & Strenta \& Elliott (1987) JEM \\
\hline $\begin{array}{l}\text { Freshman-year grades adjusted using } 13 \text { measures of students (1991) } \\
\text { enrolled in each course }\end{array}$ & A large state university & Strieker, Rock, \& Burton (1991) CB \\
\hline Comparison of several grade adjustment methods & A large state university & $\begin{array}{l}\text { Strieker, Rock, Burton, Muraki \& Jirele } \\
\text { (1992) ETS }\end{array}$ \\
\hline Item response theory scaling using a graded response model & Stanford & Young (1990a) JEM \\
\hline A general linear model with students and courses as main effects & Stanford & Young (1992) JRE \\
\hline
\end{tabular}

LSAC, Law School Admission Council research report; JES, Journal of Educational Statistics; JEM, Journal of Educational Measurement; AERJ, American Educational Research Journal; EPM, Educational and Psychological Measurement; CB, College Board research report; ETS, Educational Testing Service research report; JRE, Journal of Research in Education

these grade adjustment methods, mostly complex and sophisticated multiple regression-based equations that led to formulation of indexes, also made grades of different courses more directly comparable. ${ }^{16}$ The GWA is the local counterpart or equivalent of the GPA.

The use of grade adjustments procedure and variants has been advocated to moderate grades in a manner that would be acceptable and could ensure fairness and justifiable outcomes. ${ }^{20}$ Moreover, as it is observed that grading standards vary widely across undergraduate institutions and if GPA is considered alone during the medical school admissions process without reference to the institution attended, it will disadvantage applicants from undergraduate institutions employing rigorous grading standards. ${ }^{14}$ Didier et al. examined the validity of applying regression derived GPA institutional equating method, based on historical MCAT (Medical College Admission Test) and GPA information. Validity of the adjustment method was tested by comparing the correlation of unadjusted and adjusted GPAs with the USMLE (United States Medical Licensing Examination) performance and medical college grades. The conclusion drawn was that the institutional adjustment is consequential in the selection process as it enhances the validity of GPA in predicting academic preparedness and performance as well as performance in the licensure exam (USMLE). Furthermore, MCAT turned out to be a better indicator of academic performance than the unadjusted GPA. Likewise, raw GPA was proven to be less predictive of USMLE outcome than the MCAT; ${ }^{21}$ thus, certain adjustment of GPA must be made to enhance its predictive power.
Finally, as grade inflation has become more pervasive in many courses and in different institutions, ${ }^{3-6}$ it would be rational and fair that an adjustment method must be adopted in processing GWA. Grade inflation is defined as an increase in the grade point average with an associated increase in the student's overall ability. ${ }^{22}$ In most US universities, GPAs have increased roughly 0.15 point per decade since the 1960s with 0.67 -point increase in 1967 alone. This inflation is well documented in medical education and particularly evident in clinical setting and has been attributed mainly to a change in the academic standards as well as to student evaluation to teaching. ${ }^{8,23}$ Rapid and tremendous technological development has also contributed to higher grades because of improved student learning. Although adjusting GWA should be applied as it takes into consideration differences in courses and institutional in grading standards and systems, it does not intend to put any judgement on the course and the institution.

\section{OBJECTIVES}

The main objective of the study is to determine the validity of the $\mathrm{AF}$ in ensuring a level playing field in the admissions arena of UPCM.

Specifically, the study aims to:

1. To review changes in the admissions profile observed during the implementation of the AF

2. To describe the yearly AF per pre-medical course per campus unit from the start of its implementation 
3. To describe the mean preadmission university predicted grades (UPGs), UP College Admission Test (UPCAT) scores and high school weighted averages (HSWAs) of the different pre-medical courses

4. To describe the mean National Medical Admissions Test (NMAT) scores, pre-medical general weighted average grades (PMGWAG) and LU3 Medicine general weighted average grades (MGWAG)

5. To determine the correlation/association between the mean yearly adjustment factors and mean UPGs, UPCAT scores, HSWAs and MGWAGs

\section{OPERATIONAL DEFINITION OF TERMS}

University predicted grade (UPG). The composite score that is derived from the UPCAT score (60\%) and high school grades (40\%). It also takes into consideration the socioeconomic status and geographic domicile of the applicants. The ranking of the applicants based on the UPG is the primary basis for admissions in the University of the Philippines system.

University of the Philippines College Admissions Test (UPCAT). The nationally administered admissions test conducted by the University of the Philippines. It covers mathematics, science, language proficiency and reading comprehension. It is given annually to more than 100,000 applicants and the dominant basis for admissions of less than $15 \%$ of all examinees.

High school weighted average (HSWA). The overall grade of all high school main subjects computed according to their academic weight or the difficulty of the subject. It covers subjects mainly related to science, mathematics, and language (English and Filipino) proficiency.

Pre-medical general weighted average grade (PMGWAG). The overall grade computed from all grades obtained from the academic subjects taken in the undergraduate or pre-medical course weighted according to their corresponding units. These are prepared by the University Registrar's office and submitted by the applicants to the UPCM Admissions Office. This grade covers the three and a half years (7 semesters) of undergraduate academic performance of the student. The grading scale follows that of the UP system, wherein the highest grade is 1.0 while the lowest is 5.0 (Failed). The \% PMGWAG is computed by converting the PMGWAG to percentage using the equation \% PMGWAG $=25 \times$ (5 - PMGWAG).

National Medical Admission Test (NMAT) Score. The overall score in the nationally administered aptitude test required for admission in the medical school. This test covers the following domains: verbal and quantitative aptitude, inductive reasoning, perceptual acuity, biology, physics, chemistry and social science. The overall score, which is called the General Performance Score is given in terms of composite score and of percentile rank.
Structured interview score. The overall score obtained by the applicants in the structured interview conducted by a panel of interviewers. The instrument covers the following domains: family and school/work life, social interaction, and interest and aspirations and measures non-cognitive traits like self-awareness, honesty, stress tolerance, discipline, problem solving, work standards, flexibility, motivation, respect and concern for others. The scoring scale is from 1 to 10 , with 10 being the highest. The overall score of the applicant is the average score from all interviewers. For the uniformity of scales in the regression analysis, this interview score is converted to percentage.

Medical general weighted average grade (MGWAG). The overall grade computed from the grades of the courses taken during the medicine proper program, adjusted according to their corresponding unit-hours. These are computed prior to graduation by the Office of Students Records of UPCM and kept as part of the student's permanent archival record. The scale follows the UP-grading scale, with 1.0 the highest and 5.0 the lowest (Failed). The \% MGWAG is likewise computed by converting the MGWAG into percentage by the equation: $\% \mathrm{MGWAG}=25 \times(5-\mathrm{MGWAG})$

Learning Unit 3 (LU 3). The equivalent of first year medicine proper. This is also the freshman year in the UP College of Medicine. This unit covers all the medical basic sciences like human anatomy, biochemistry, physiology, histology, and other courses taught in an organ system integrated (OSI) approach.

Lateral Entrants. Those who were accepted in UPCM, after obtaining a 4-year baccalaureate degree. They entered the college as freshmen in LU 3

\section{METHODS}

This research work is part of a continuing review and formative evaluation of the new admissions policy in UPCM, which is currently on its fifth year of implementation. This study has both descriptive and analytic designs utilizing records and documentary data of lateral entrants. Most of these records and data were obtained from the Office of Admissions of the University of the Philippines in Diliman, Quezon City and the Admissions Office of UPCM in UP Manila.

The Office of Admissions of the UP System provided the pre-admission data which included UPG, UPCAT Scores and HSWA of all successful applicants to the different premedical courses of UP System. The data covered the period of 11 years (2008--2018) and involved 6,756 applicants. These data were analyzed and described.

Yearly computed AF for different pre-medical courses of lateral entrants were retrieved from the Admissions Office of UPCM and analyzed. These are numerical coefficients that are incorporated in the computation of pre-medical GWAG. The AF aims to standardize and make comparable the different grading scales and systems of the different 
pre-medical courses, schools and university units/colleges. The numerator of the AF is the NMAT performances of previous batches of a particular course, of a particular college within a given time frame (5 years). It factors in the average GWAGs obtained by the same batches within 5 years as the denominator. The square root of this ratio will be the $\mathrm{AF}$ and will be used to standardize or normalize of grading system of the said course (Equation 1).

$$
\mathrm{AF}=\sqrt{\frac{\overline{\mathrm{NMAT}_{i}}}{\overline{\text { \%MGWAG }_{i}}}}
$$

Where:

$\mathrm{NMAT}_{i}$ is the mean NMAT score of the lateral entrantapplicants coming from a particular course and school, from the last five years.

\%PMGWAG ${ }_{i}$ is the mean pre-medical GWA (in percentage) of the lateral entrant-applicants coming from a particular course and school, from the last five years.

The AF is incorporated with and will adjust the individual pre-medical GWA (PMGWA). It has a value near 1.000. From Equation 1, batches and pre-medical courses that had garnered higher NMAT averages, as the mean NMAT score is placed as the numerator, would obtain higher $\mathrm{AF}(>1.000)$. On the other hand, higher mean PMGWAGs (in percentage) would lead to lower AF ( $<1.000)$, as the mean PMGWAG is the denominator. A higher mean NMAT score indicates academically brighter students, thus, expectedly a higher AF. On the other hand, a higher mean \% PMGWAG assumes that the pre-medical course is easy or easily gives high grades; thus, a lower AF.

The adjusted GWA is then used to compute the admission index (AI) based on the formula below (Equation 2). The admission index is primarily the basis of the lateral entrant-applicant's ranking and the final determinant of admission.

\section{Admission Index (Al): Equation 2 \\ $\mathrm{Al}=0.60 \times \mathrm{AF} \times \% \mathrm{PMGWA}+0.30 \times \mathrm{NMAT}+0.10 \times \mathrm{IS}$ \\ Where: \\ IS is the interview score of the applicant}

\%PMGWA is the lateral entrant-applicant's pre-medical General Weighted Average (GWA) in percentage

NMAT is the lateral entrant-applicant's NMAT score in percentile

The AF is annually computed and is specific for individual pre-medical courses, units (university/college/ campus) graduated from, and the application year. As can be seen in Equation 2, the AF is incorporated into the \% PMGWAG as its coefficient in the determination of the admission index. A high AF (>1.000) would increase the admission index, as it increases the adjusted \% PMGWA. The reverse is true, as a lower $\mathrm{AF}(<1.000)$ reduces the adjusted \% PMGWA and consequently the admission index, which is the main determinant of the applicants' ranking and the ultimate basis of admission.

In this study, the traceback pre-admission data including UPG, UPCAT scores and HSWA corresponding to specific pre-medical courses were described and correlated with their adjustment factors. The corresponding five-year average profile of NMAT, PMGWAG and LU3 MGWAG of the different pre-medical courses were likewise described. The LU 3 MGWAG was correlated with their AF.

\section{Ethical Consideration}

Official permission from the Office of the UPCM Dean was obtained to access archival documents and records from the Student Records Office and the Admissions Office. The purpose, the design as well as the mechanics of the study were explained to the Dean and to the staff of the abovementioned offices.

Confidentiality of records and documents to be retrieved and reviewed the anonymity of the identity as well relative to these records and documents were strictly maintained. Privacy of the individuals to whom these records and documents pertain was always protected.

To ensure the confidentiality of information and to protect the privacy of the record owners, anonymization and de-identification were implemented through complete encoding of the identities and information. Instead of names, numbers were assigned to each, and every record obtained. At no given instance were names or identifiers appeared on any record/data encoded. The principal investigator, being familiar with some of the record owners was not involved in the encoding of the identifications and data, nor had access to the decoded information. The principal investigator was totally blinded on the ownership of the record and data at all times.

Furthermore, only the research assistant did the encoding of identity and information. The research assistant was recruited based on, among other things, computer literacy. It was absolutely required that the said research assistant was not from the medical community, the college, nor from the UP system, to ensure unfamiliarity with any of the record/ data owners. The research assistant was required to sign a confidentiality/non-disclosure agreement.

Individual consent was deemed unnecessary and was not obtained as this study was a retrospective analysis of archival records and documents in anonymity. Neither identity nor identification was attached to the records and documents used in the study.

Lastly as a mandatory requirement for all research studies in this institution and for the purpose of future publication, the author of this undertaking personally worked for and had obtained waiver of consent, technical and ethical approval 
from Research Implementation and Development Office (RIDO) and University of the Philippines, Manila Review Ethics Board (UPMREB).

\section{RESULTS}

\section{Yearly Adjustment Factors and Pre-Medical Courses}

The top three pre-med courses with high mean adjustment factors were all from the UP Manila and belonging to the less-frequent pre-medical courses accepted at UPCM (Table 2). They were not the traditional pre-medical courses and constituted only a total of less than 10 admissions per course (out of 180) yearly. ${ }^{24-26}$ These pre-medical courses were BS Pharmacy UPM, BS Applied Physics UPM and BS Computer Science UPM. Traditional pre-medical courses from UP Manila had higher mean adjustment factors than those from UP Diliman. The traditional pre-medical courses from UP Diliman that garnered lower adjustment factors were BS Psychology UPD, BS Molecular Biology and Biotechnology (MBB) UPD and BS Biology UPD.

\section{UPG, UPCAT, HSWA and Pre-Medical Courses}

In terms of pre-admission mean university predicted grades (UPG) of the different pre-medical courses for the past eleven years (2008-2018), UP Diliman pre-med courses (red bars) romped ahead over those pre-medical courses from UP Manila (blue bars) (Figure 1). Out of 6,756, the mean UPG of BS MBB UPD ( $\mathrm{n}=521)$ was $1.79(\mathrm{SD}=0.15)$ and was the highest among the different pre-medical courses, followed by BS Biology UPD (1.98, SD=0.18, $\mathrm{n}=996)$ and BS Psychology UPD (2.00, $\mathrm{SD}=0.19, \mathrm{n}=825)$. The lowest three were all from UP Manila, namely BS Computer Science UPM (2.24, SD=0.12, $\mathrm{n}=441)$, BS Applied Physics $\mathrm{UPM}(2.22, \mathrm{SD}=0.13, \mathrm{n}=170)$ and BS Nursing UPM $(2.14$, $\mathrm{SD}=0.11, \mathrm{n}=598)$. These lowest three had 1 the highest adjustment factors (Table 2). The UP-grading system is a numerical rating system, ranging from 1.0 to 5.0 with 1.0 being the highest and 5.0, a failing grade.

The same pattern was likewise observed with the mean preadmission UPCAT scores (percentage) among the different pre-medical courses during the same period (20082018) (Figure 2). The highest mean UPCAT scores among the different pre-medical courses were courses from UP Diliman, namely BS MBB UPD (73.7, SD=3.1), followed by BS Biology UPD (69.9, SD=4.1) and BS Psychology UPD (69.4, $\mathrm{SD}=4.0$ ). All of these were traditional pre-medical courses. The lowest three mean UPCAT scores were non-traditional pre-medical courses from UP Manila, namely BS Applied Physics UPM (63.6, SD=4.0), BS Computer Science UPM (64.2, $\mathrm{SD}=3.6$ ) and BS Nursing (UPCAT=64.8, $\mathrm{SD}=3.6$ ).

A slight variation in pattern of ranking can be seen in their mean high school weighted averages (HSWA), where BS MBB UPD (91.5, SD=1.7) remained the topnotcher, followed by BS Public Health UPM $(90, \mathrm{SD}=1.6)$ and BS Nursing UPM (90.4, SD=1.8). The bottom three were BS Applied Physics UPM (88.7, SD=2.1), BS Computer Science UPM (88.9, SD=1.9) and BS Psychology UPD (89.7, $\mathrm{SD}=0.75$ ) (Figure 3). In between were the rest of the premedical courses, and exhibited no trend or perceptible pattern similar to that of mean UPG and UPCAT, with differences of only 0.2 percent or less from each other. The HSWA presented below were not yet adjusted and still unstandardized.

\section{NMAT, PMGWAG, MGWAG and Pre-Medical Courses}

Figure 4 shows the five-year mean NMAT scores of the different pre-medical courses from 2014 to 2018 involving 2,606 applicants to UPCM. Two pre-medical courses from UP Diliman namely BS MBB (98.71, SD=1.66) and BS Biology (98.37, $\mathrm{SD}=2.08$ ) garnered the top posts followed by BS Biology from UP Manila (98.36, $\mathrm{SD}=2.14)$, while the

Table 2. Annual Adjustment Factors by Pre-med Courses (2017-2020)

\begin{tabular}{lllllcc}
\multicolumn{1}{c}{ Pre-Med Courses } & $\mathbf{2 0 1 7}$ & $\mathbf{2 0 1 8}$ & $\mathbf{2 0 1 9}$ & $\mathbf{2 0 2 0}$ & Mean & Std. Dev. \\
\hline BS Pharmacy UPM & 1.068 & 1.112 & 1.112 & 1.108 & 1.100 & 0.021 \\
BS Applied Physics UPM $^{*}$ & 1.054 & 1.106 & 1.106 & 1.074 & 1.085 & 0.026 \\
BS Computer Science UPM $^{*}$ & NA $^{\ddagger}$ & 1.106 & 1.055 & NA $^{\ddagger}$ & $1.080^{\S}$ & 0.036 \\
BS Chemistry UPD* $^{*}$ & 1.043 & 1.084 & 1.084 & 1.082 & 1.073 & 0.020 \\
BS Nursing UPM $^{*}$ & 1.050 & 1.055 & 1.055 & 1.084 & 1.061 & 0.016 \\
BS Biology UPM $^{\dagger}$ & 1.037 & 1.064 & 1.064 & 1.068 & 1.058 & 0.014 \\
BS Public Health UPM $^{\dagger}$ & 1.040 & 1.051 & 1.051 & 1.040 & 1.045 & 0.006 \\
BS Biochemistry UPM $^{\dagger}$ & 1.024 & 1.046 & 1.046 & 1.057 & 1.043 & 0.014 \\
BS Biology UPD $^{\dagger}$ & 1.029 & 1.044 & 1.044 & 1.043 & 1.040 & 0.007 \\
BS MBB UPD $^{\dagger}$ & 0.983 & 0.980 & 0.980 & 0.992 & 0.984 & 0.006 \\
BS Psychology UPD $^{\dagger}$ & 0.970 & 0.963 & 0.963 & 0.956 & 0.963 & 0.006 \\
\hline
\end{tabular}

* Less frequent/ non-traditional pre-med courses in UPCM

+ Most frequent/ traditional pre-med courses in UPCM

¥ Not enough sample size

$\S$ Computed from 2018 and 2019 


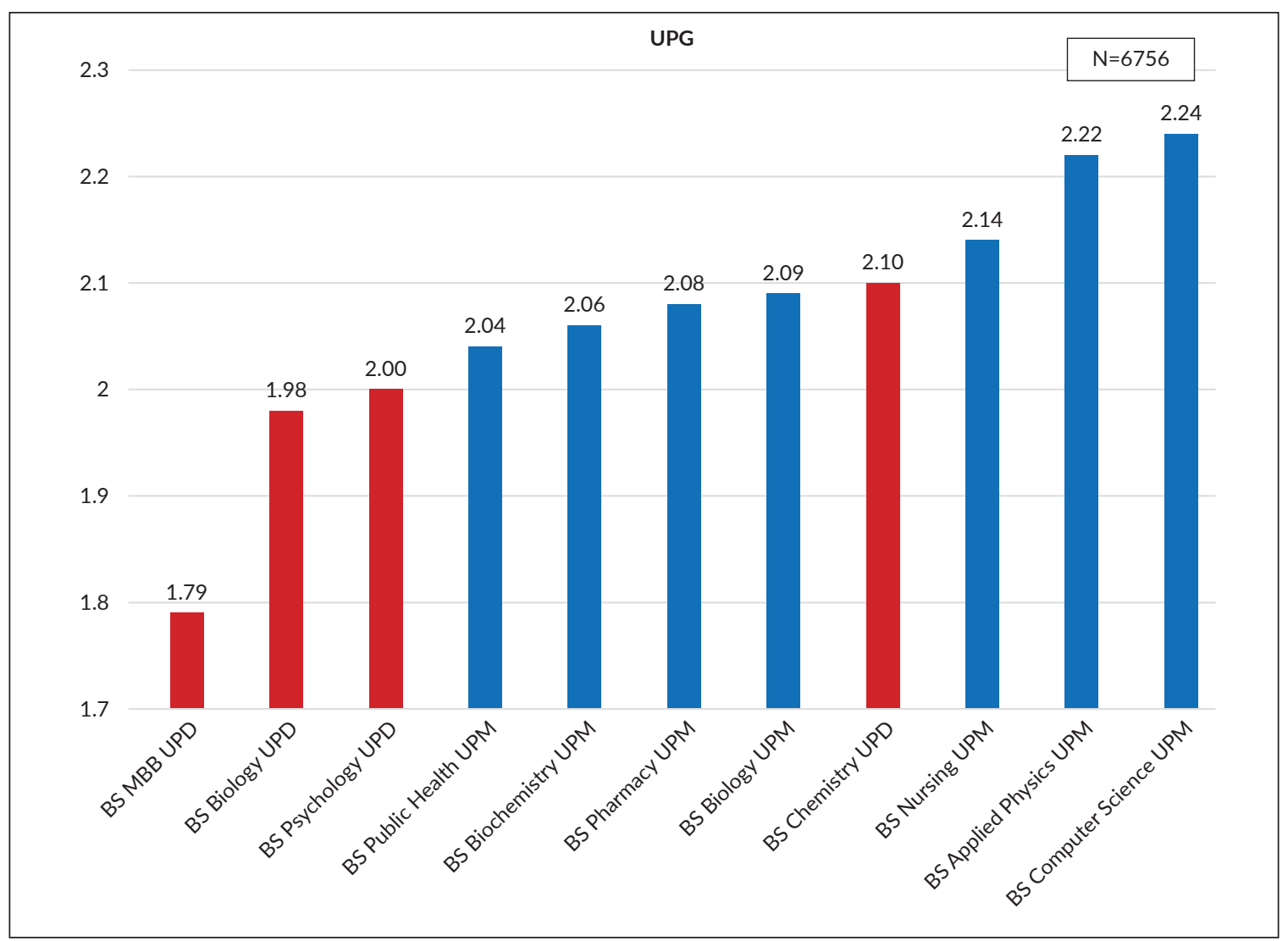

Figure 1. Mean university predicted grade (UPG) of different pre-med courses, Academic years (2008-2018).

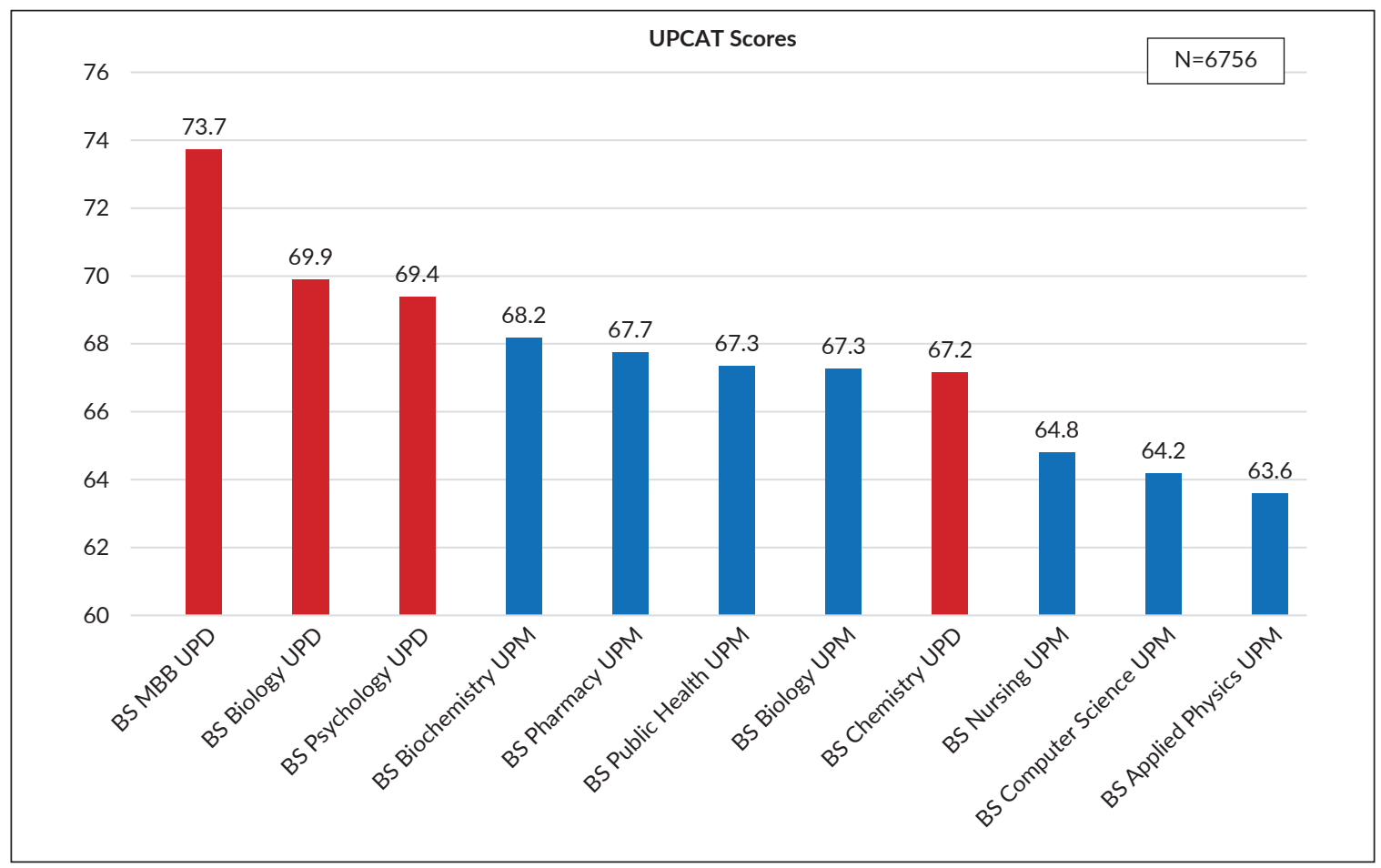

Figure 2. Mean UP College Admissions Test (UPCAT) scores (\%) of different pre-medical courses (2008-2018). 


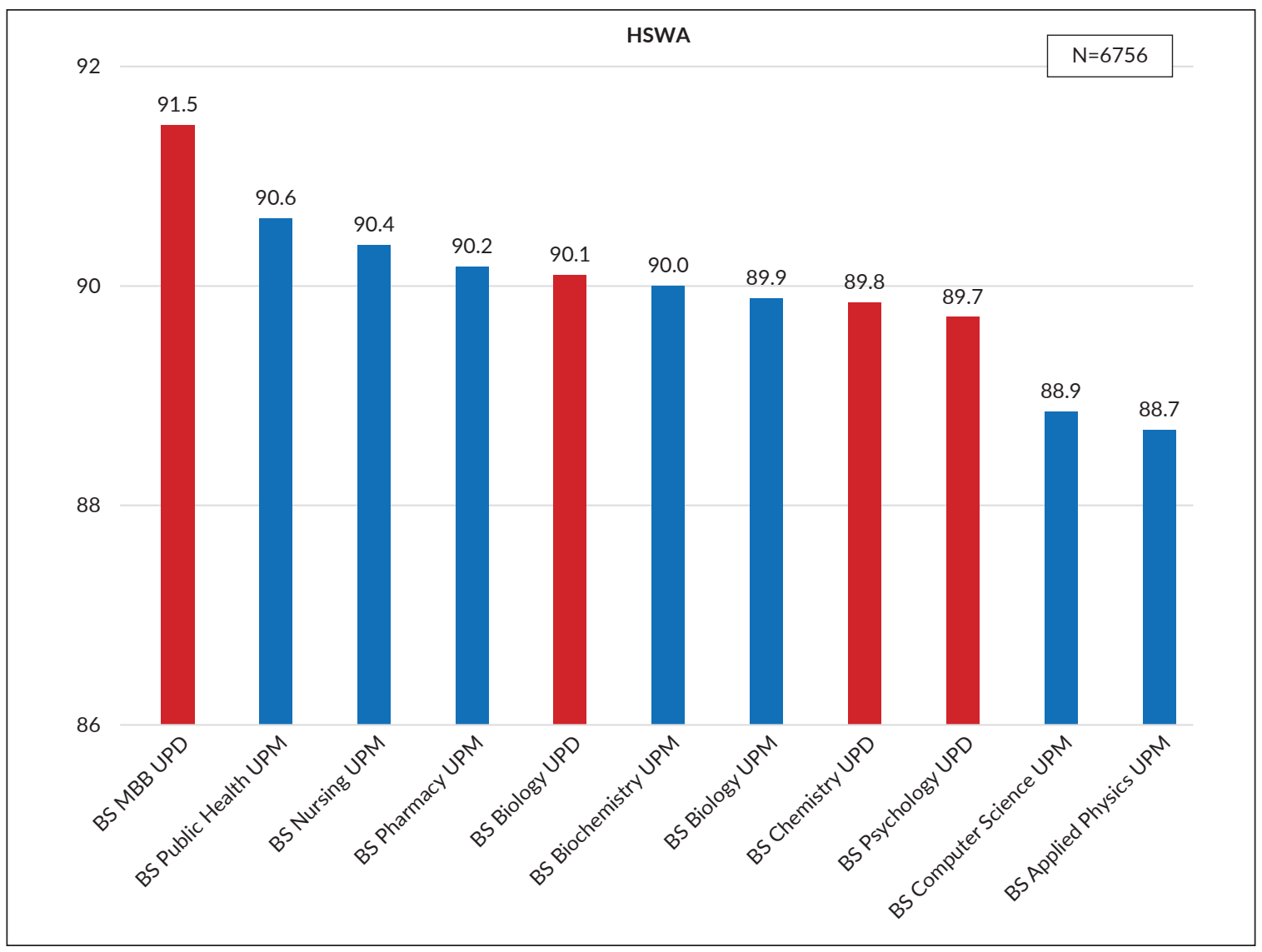

Figure 3. Mean High School Weighted Average (HSWA) of different pre-medical courses (2008-2018).

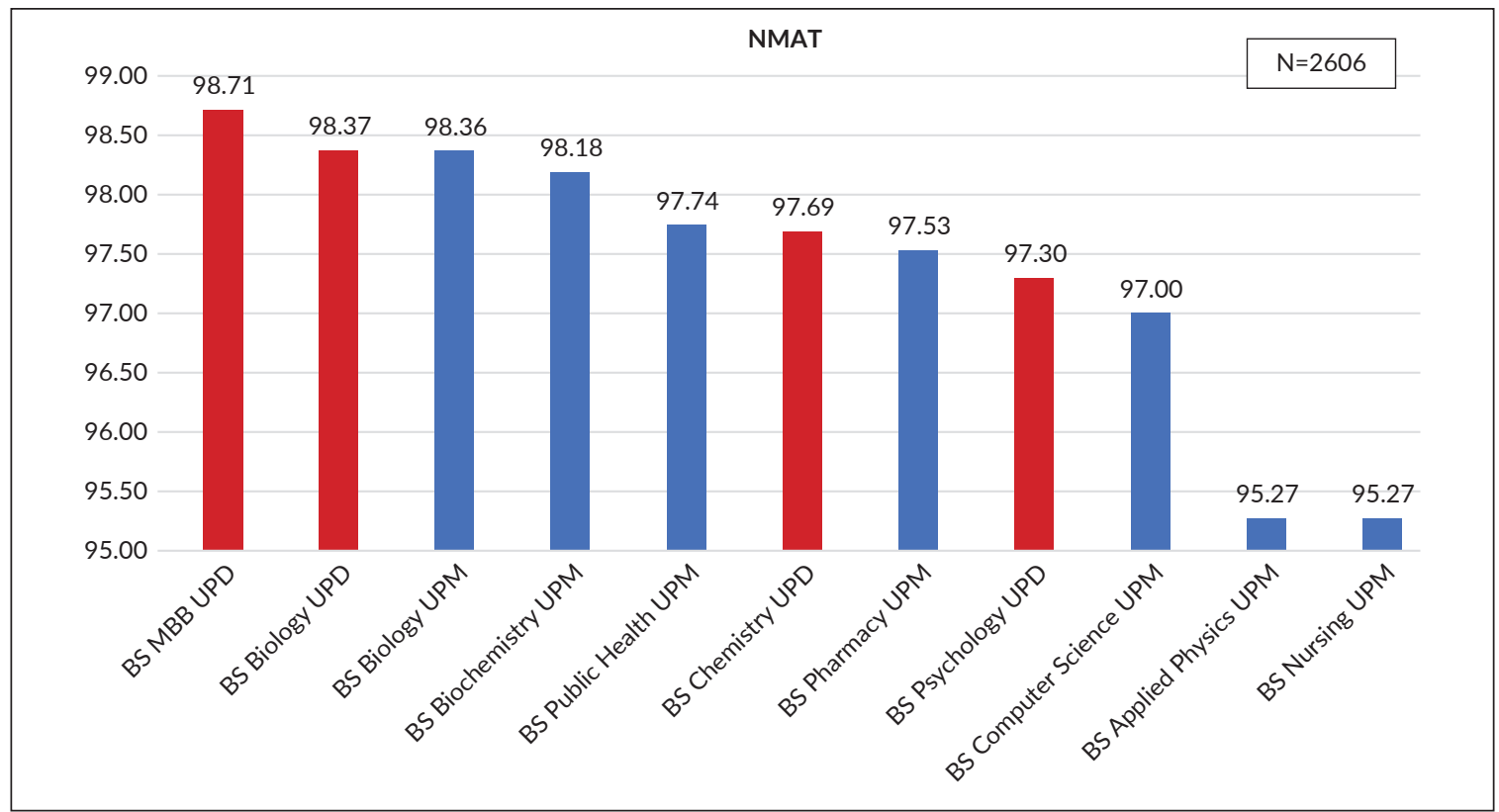

Figure 4. Mean National Medical Admissions Test (NMAT) of different pre-medical courses (2014-2018). 


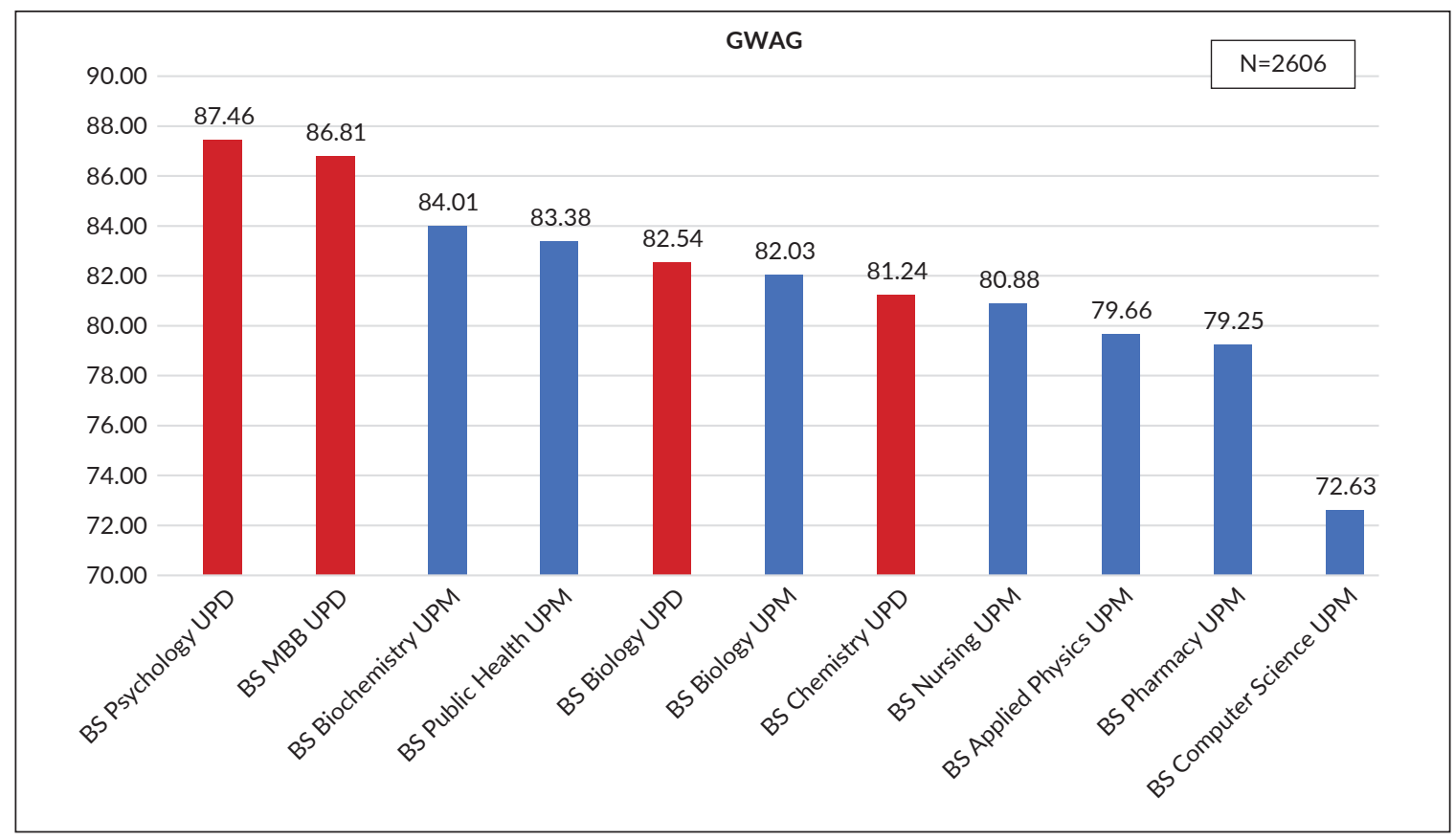

Figure 5. Mean General Weighted Average Grades (GWAG) of different pre-med courses (2014-2018).

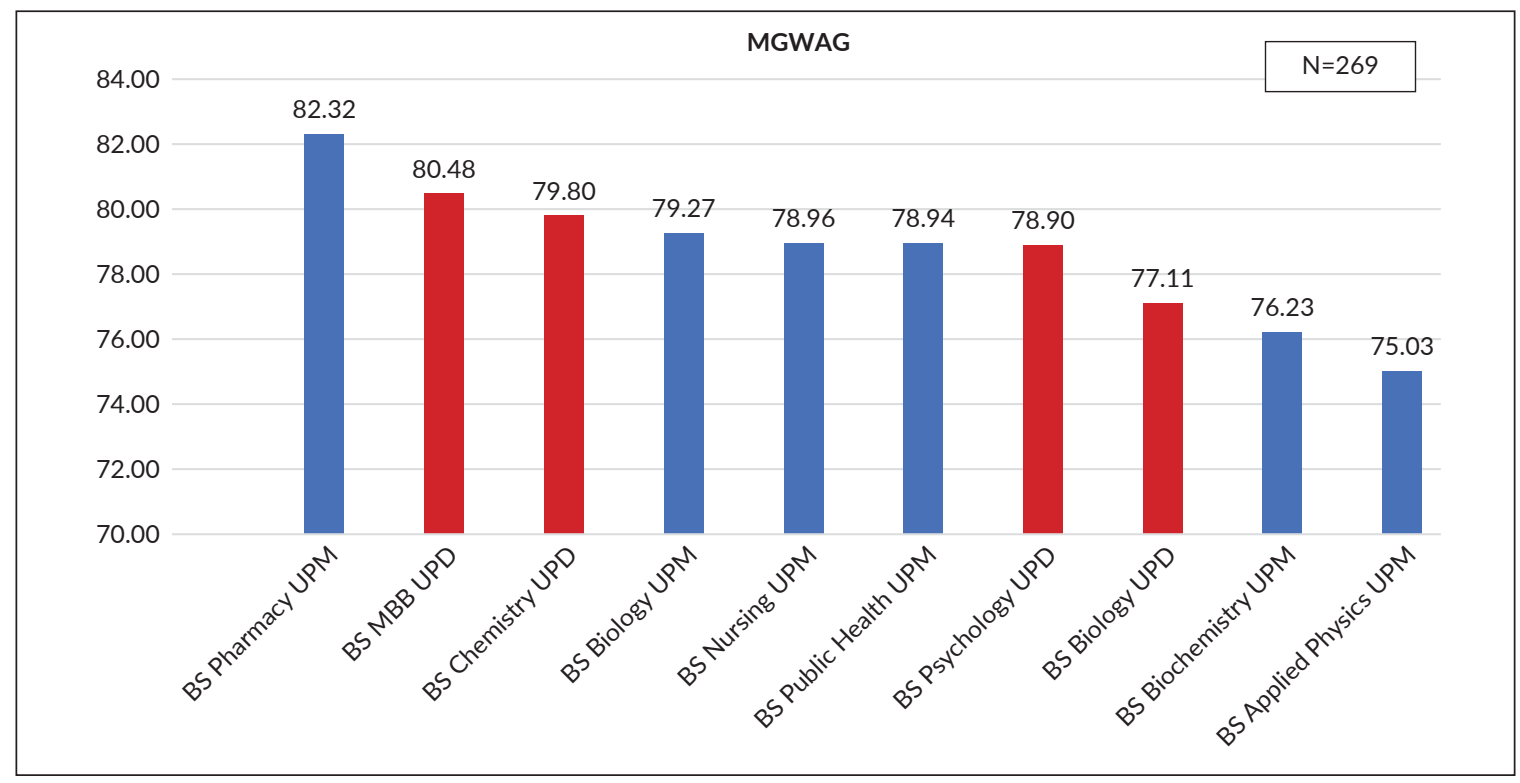

Figure 6. Mean Medical General Weighted Average Grades: LU3 (MGWAG) of different pre-medical courses (Class 2022-2023).

lowest two pre-med courses were BS Applied Physics UPM (95.27, $\mathrm{SD}=1.62)$ and BS Nursing UPM (95.27, $\mathrm{SD}=3.02$ ). These last pre-med courses from UP Manila scored drastically lower than the third lowest, BS Computer Science (97.00, $\mathrm{SD}=1.00)$. Between the highest and the lowest were premedical courses with mean NMAT scores that were not very different from each other.

Figure 5 is the profile distribution of the five-year mean GWAG of the different pre-medical courses from 2014 to
2018 involving 2,606 applicants to UPCM. Pre-medical courses that posted the highest were BS Psychology UPD (87.46, SD=4.92) and BS MBB UPD (86.81, SD=4.84), followed on third by BS Biochemistry of UPM (84.01, $\mathrm{SD}=5.32$ ) The lowest three were BS Computer Science UPM (72.63, $\mathrm{SD}=3.99)$, BS Pharmacy UPM (79.25, SD=7.26), and BS Applied Physics UPM (79.66, SD=7.02). BS Computer Science UPM showed the most drastic fall in GWAG from the tail end of the profile. 


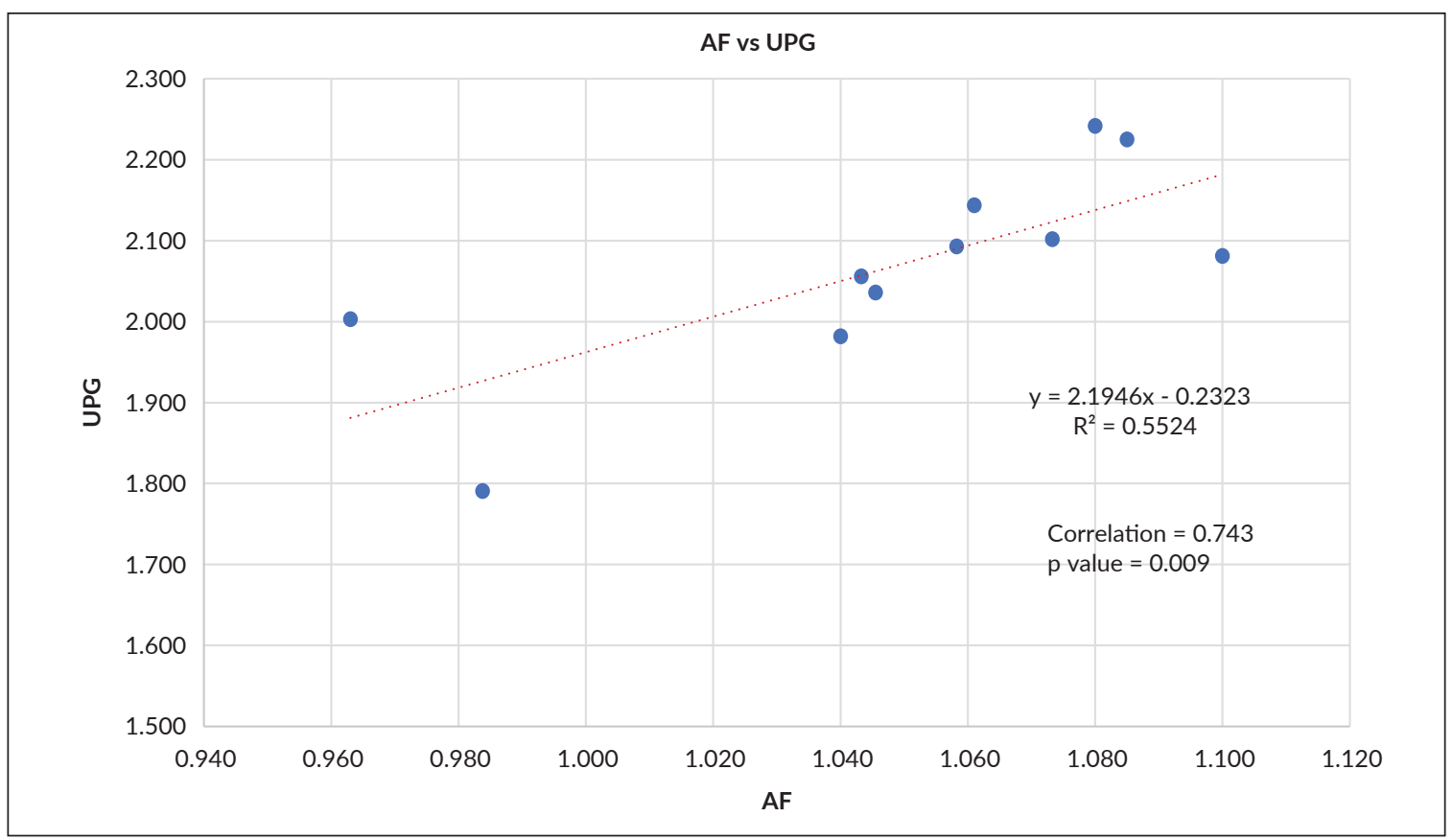

Figure 7. Correlation between yearly adjustment factors (AF) vs mean University Predicted Grades (UPG).

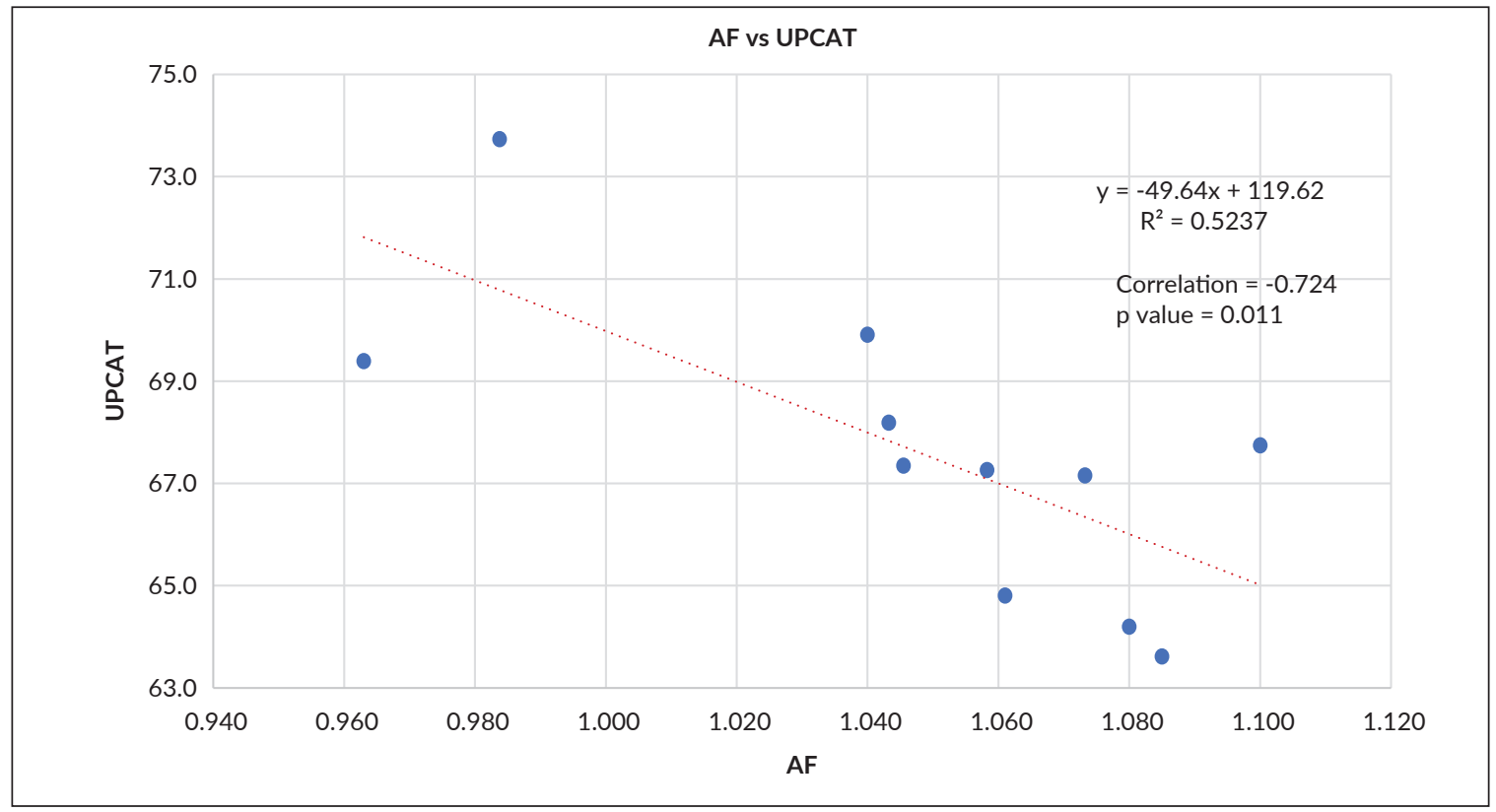

Figure 8. Correlations between yearly adjustment factors (AF) vs mean UP College Admissions Test (UPCAT) scores.

Figure 6 shows the profile distribution of mean LU3 Medical General Weighted Average Grades (MGWAG) of the different pre-medical courses. These were taken from all 269 UPCM medical students of Class 2022 and Class 2023, who entered the college as lateral entrants. Topping the list was BS Pharmacy UPM (82.32, $\mathrm{SD}=5.13)$, which also had the highest mean adjustment factor (1.1000) (Table 2). The second and third in rank, were BS MBB UPD (80.48,
$\mathrm{SD}=4.91)$ and BS Chemistry UPD (79.80, SD=4.90) respective. The second rank, BS MBB UPD, ranked second to the last in the list of the designated adjustment factor (Table 2). The lowest ranked pre-medical courses in the profile were BS Applied Physics UPM (75.03, SD=6.08) and BS Biochemistry UPM (76.23, $\mathrm{SD}=2.76)$. The third lowest in rank was BS Biology UPD (77.11, SD=4.87). 


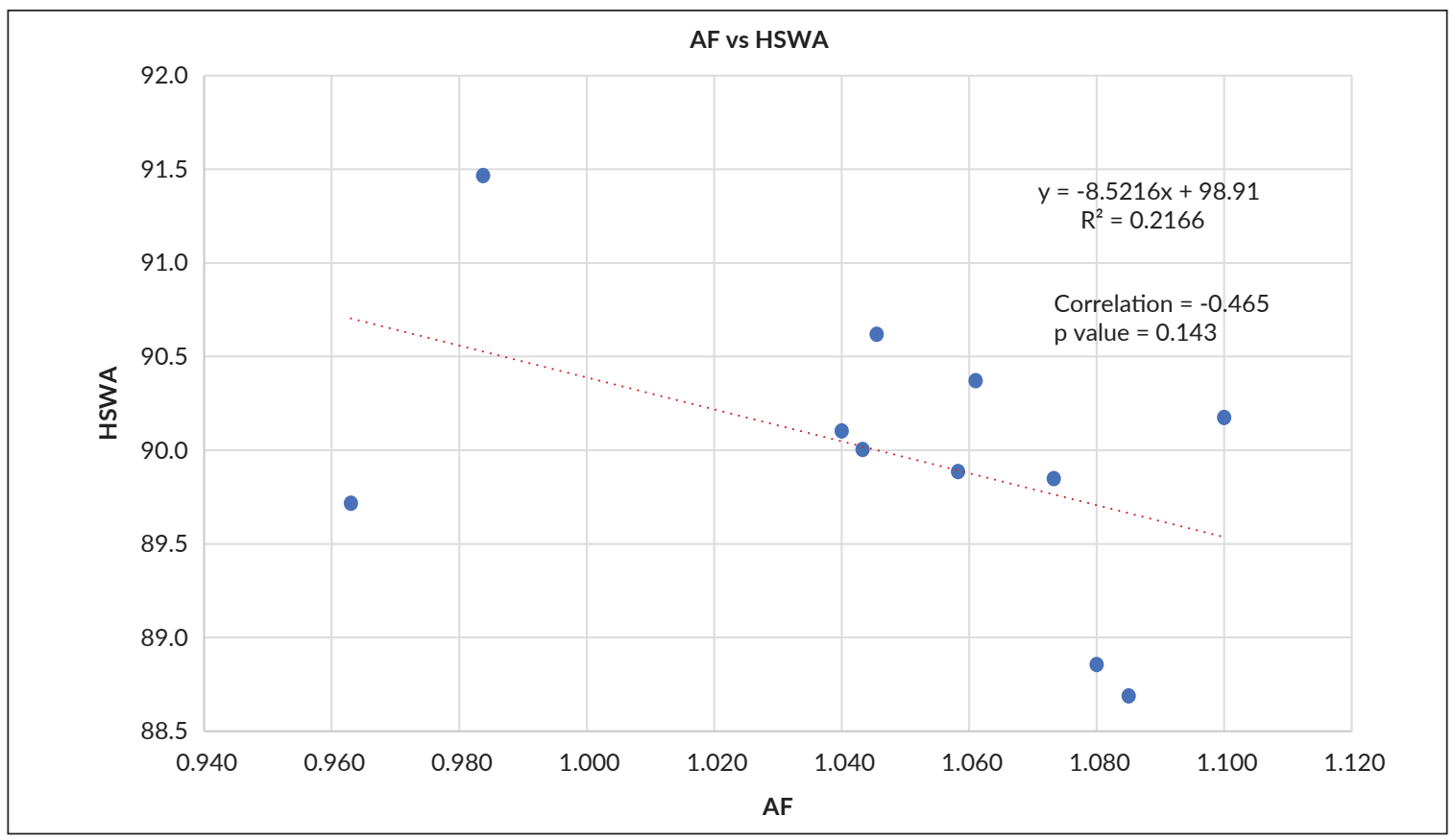

Figure 9. Correlations between yearly adjustment factors (AF) vs mean High School Weighted Average (HSWA).

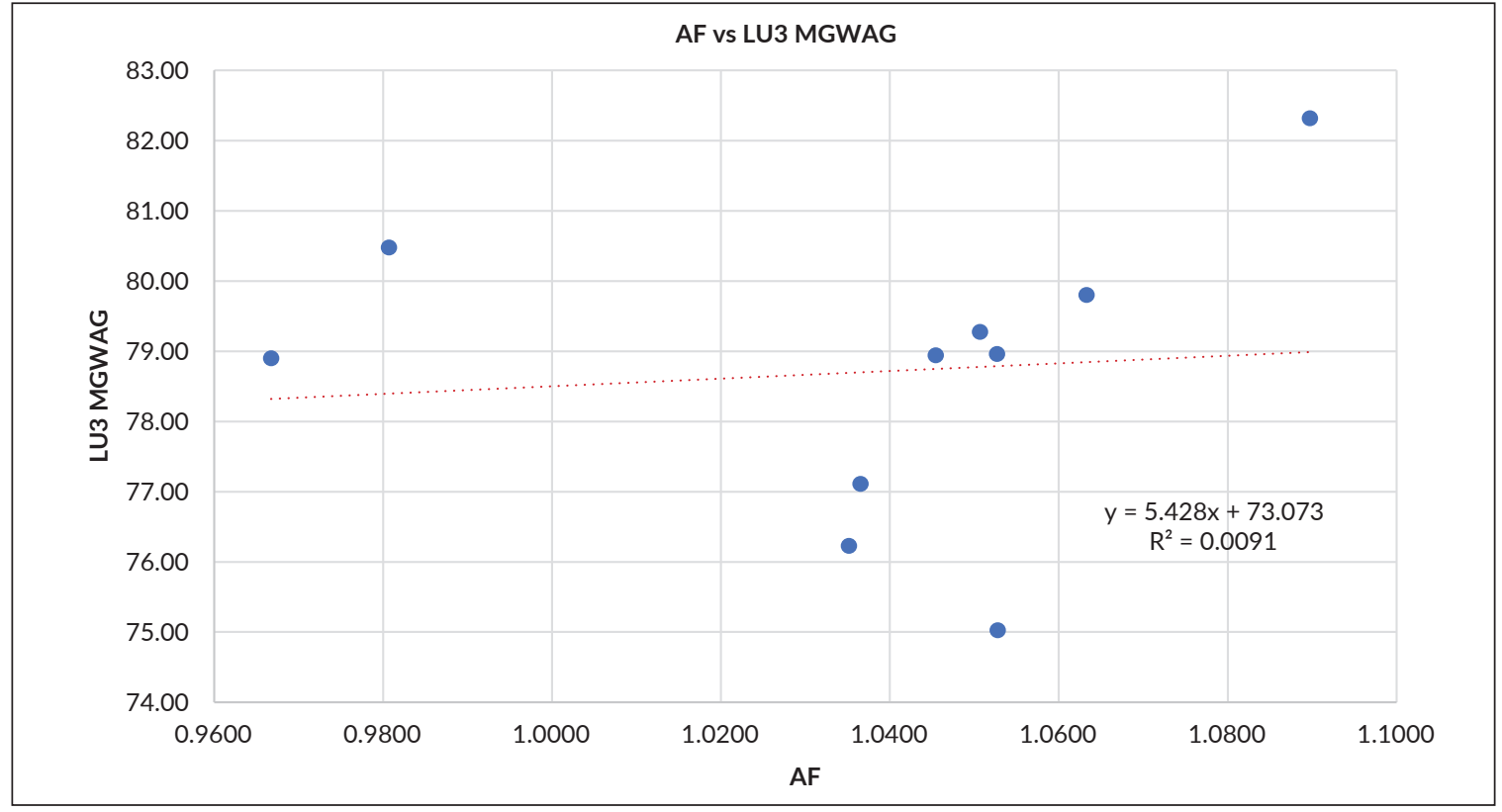

Figure 10. Yearly adjustment factors (AF) vs mean LU3 Medical General Weighted Average Grades.

\section{Correlations of UPG, UPCAT, HSWA and MGWAG (LU3) with Adjustment Factors}

The mean yearly adjustment factors of the above premedical courses plotted against their mean UPG established a direct strong correlation (Figure 7). The regression model showed a positive regression coefficient $(+2.1946)$ indicating a direct correlation, while the coefficient of determination $\left(\mathrm{R}^{2}=0.5524\right)$ indicates a moderately strong size effect or that the model fits the data moderately. Two-tailed Pearson's correlation shows a strong and statistically significant association with a correlation coefficient of 0.743 . This regression model propounds that a better UPG is associated with a lower adjustment factor.

On the other hand, the mean yearly adjustment factors of the different pre-medical courses plotted against their mean UPCAT scores showed a strong but inverse correlation (Figure 


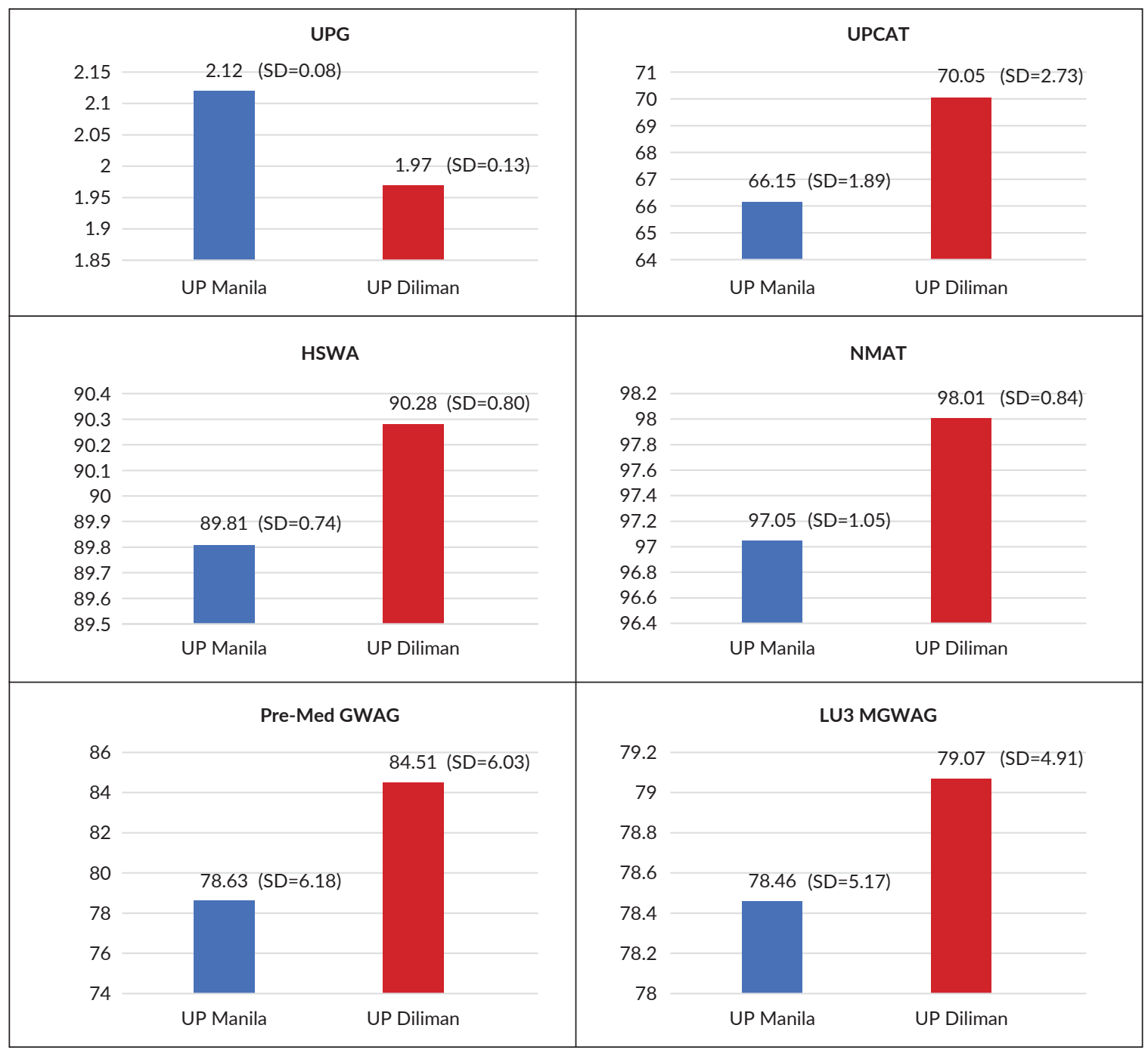

Figure 11. Mean UPG, UPCAT, HSWA, NMAT, pre-Medical GWAG and LU3 MGWAG: UP Manila vs UP Diliman.

8). A negative regression coefficient (-49.64) indicated an inverse correlation with a moderate size effect $\left(\mathrm{R}^{2}=0.5237\right)$. The inverse correlation was likewise strong with a statistically significant correlation coefficient of -0.724 (Two-tailed Pearson's correlation). The model put forward that a higher UPCAT score is associated with a lower adjustment factor.

The mean annual adjustment factors of the different premedical courses plotted against their mean HSWAs likewise revealed an inverse correlation (Figure 9) with a negative regression coefficient $(-8.5216)$. However, the coefficient of determination was small $\left(\mathrm{R}^{2}=0.2166\right)$, indicating the model's small size effect. Furthermore, the correlation between the mean annual adjustment factors and mean HSWAs was not statistically significant ( $p$ value $=0.143$ ). It should be noted that the HSWAs were neither standardized nor adjusted.

Figure 10 shows the plot of the yearly mean adjustment factors of the different pre-medical courses with their corresponding mean LU3 medical general weighted average grades (MGWAG). There was a very small size effect
$(\mathrm{R}$-squared $=0.0091)$, but it was not a statistically significant correlation (Pearson's Correlation coefficient $=0.095$, Sig. $[2$-tail $]=0.795)$.

UPG, UPCAT, HSWA, NMAT, PMGWAG, MGWAG (LU3) and UP Campuses

Pre-medical courses from UP Diliman generally outperformed those from UP Manila as follows, UPG (1.97 vs 2.12), UPCAT (70.05 vs 66.15), HSWA (90.28 vs 89.81 ), NMAT (98.01 vs 97.05), Pre-med GWAG (84.51 vs 78.63) and LU3 Medicine GWAG (79.07 vs 78.46) (Figure 11). Despite this, pre-medical courses from UP Manila (1.068) had higher mean adjustment factors than those from UP Diliman (1.015) (Figure 12).

\section{DISCUSSION}

The grade adjustment scheme was conceptualized, formulated, and implemented for the simple purpose of 


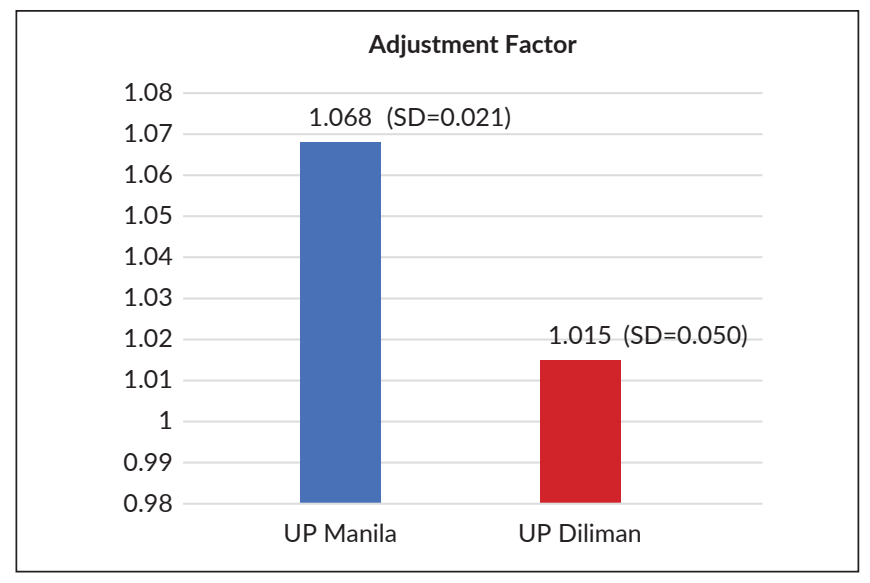

Figure 12. Mean adjustment factors: UP Manila vs UP Diliman.

leveling the playing field among all aspirants to UPCM. Applicants come from a wide variety of campuses/colleges/ institutions and graduate from different pre-medical courses and adopting different grading systems and standards. This adjustment process aims to minimize the undue advantages of those graduating from "easy-to-get-high-grades" premedical courses and colleges. Since the implementation of the recently amended admissions policy in 2017, there were major changes observed in the admission profile of UPCM that were attributed to the administration of adjustment factors in the recalculation of GWA. ${ }^{26}$

The adjustment of the premedical GWA brought forth the following issues: 1.) Significant and continuous decline in the yearly mean GWA and mean NMAT among accepted students of UPCM, 2.) Drop in the number of accepted applicants with high honors (summa cum laude and magna cum laude) and rise in the admissions of cum laude graduates and those without Latin honors, 3.) Admissions ratio reversal between graduates of UP Diliman and UP Manila, where UP Diliman used to dominate the admissions, 4.) Abrupt reduction in admissions of BS Psychology UPD, and 5.) Continuous rise in admissions of BS Public Health UPM and BS Pharmacy UPM. These changes were all indicative of lowering the bar of admissions credentials and the quality of students being accepted at UPCM. ${ }^{26}$

This study further substantiated the attribution of the lowering of academic qualifications of UPCM accepted students to the implementation of grade adjustment scheme. The adjustment factors are computed based on the ratio between NMAT and GWA, wherein mean NMAT is the numerator and mean GWA as the denominator. The effect of high mean NMAT is toward a higher adjustment factor and higher adjusted GWA. Courses whose graduates did not perform well in NMAT bear the burden of down-graded adjusted GWAs through a lower adjustment factor. At this point, the grade adjustment seems fair and logical as well.

On the other hand, the mean GWA is placed in the denominator mainly for the purpose of "neutralizing" the effects of the grade inflation or overrated GWA. If the mean GWA surpasses the mean NMAT, then the adjustment factor as a ratio becomes lower than 1.0. Thus, through a low computed adjustment factor (below 1.0) the adjustment ratio downgrades the adjusted GWAs from courses and colleges that are known to give high grades. The adjustment formula assumes that all high GWAs were all due to grade inflation, easy pre-medical course and to a certain degree, academic leniency and generosity. Thus, adopting this assumption and applying Equation 1 formula in the computation of adjustment factors with GWA being in the denominator puts the burden of lower adjustment factors to those pre-medical courses with high GWAs. However, what if the high GWAs were due to intrinsically brilliant students who performed well academically and not due to overrated grading? This is where the bone of contention lies.

As it is difficult to prove the existence of grade inflation and academic leniency/generosity, more so to determine the level of course difficulty, it is nevertheless quite straightforward to prove that high GWAs were due to good academic performance of "inherently bright" students. The innate intelligence of students can be gauged easily from their previous academic performance (HSWA), previous admissions rating (UPG) and previous performance to a standardized examination (UPCAT scores). More recently, this intrinsic academic smartness can be reflected on their NMAT performance and PMGWAGs and LU3 MGWAGs.

Furthermore, if the high GWAs (denominator in the adjustment factor) were mainly due to intrinsically brilliant students (High UPGs, UPCAT scores, HSWAs, NMATs, PMGWAGs, MGWAGs), then this would invalidate the assumption on which the formula for adjustment factor was grounded. And worse, if the invalidity is proven factual, then the application of adjustment factors would not only be unfair but would also constitute an unmitigated injustice, for those who did very well academically in their premedical courses but were denied admissions because of low adjustment factors.

The study has shown that pre-medical courses from UP Diliman had lower adjustment factors compared to UP Manila. This was shown despite the fact that those accepted at UP Diliman in any 4-year baccalaureate course had a generally higher admissions cutoff (UPG) than those of UP Manila. ${ }^{27}$ And furthermore, this was shown despite the fact that UP Diliman had higher and better mean UPG, UPCAT, HSWA, NMAT, PMGWAG and LU3MGWAG than UP Manila.

The study also has shown the top three premedical courses in terms of the mean UPGs in the past 11 years, namely BS MBB UPD, BS Biology UPD and BS Psychology UPD, were also the same premedical courses that garnered the lowest adjustment factors in the past four years. Similarly, the lowest two premedical courses in terms of mean UPGs, namely BS Computer Science UPM and BS Applied Physics UPM, were in the list oof top three highest mean adjustment 
factors. This pattern was in parallel with those observed in mean NMAT and mean GWAG. This indicates that there was an inversion in the relationship between mean adjustment factors and mean UPG, as well as the mean NMAT and mean GWAG.

Similarly, the top three pre-medical courses in mean UPCAT, namely BS MBB UPD, BS Biology UPD and BS Psychology UPD, were also the lowest in the list of mean adjustment factors. On the other hand, the lowest three in the mean UPCAT were also on the top of the list of high adjustment factors, namely BS Applied Physics UPM, BS Computer Science UPM and BS Nursing UPM. This observation indicates an inverse relationship between mean UPCAT scores and mean adjustment factors. The similarities in the trends seen in both the mean UPGs and UPCAT scores of the different pre-medical courses can be explained by that fact that the derivation of UPG uses UPCAT score as a major addend. In fact, $60 \%$ of the UPG is derived from the UPCAT score.,28

The top notched for mean HSWAs was still BS MBB UPD and the lowest were BS Applied Physics UPM and BS Computer Science UPM. Between the highest and the lowest, were courses whose ranking pattern deviated from that of the mean UPGs and mean UPCAT scores. This deviation may be attributed to the HSWAs being the ratings from highly heterogenous high schools with wide variation in grading standards and grading systems. HSWAs were not standardized and adjusted.

The high ranking of pre-medical courses, in terms of mean UPG, mean UPCAT scores and mean HSWAs, generally indicates intellectual superiority. Thus, expectedly they too would have better GWAs upon graduation. It is apparent that their good GWAs can be directly attributed to their intrinsic intellectual capability and not to grade inflation, academic leniency, and easy course. It is ironic and worse, unfair that they must bear the burden of low AF due to their high GWAs.

It is apparent that validity of the AF applies exclusively to BS Pharmacy UPM, wherein it topped both the mean yearly AF and mean LU3 MGWAG. However, the rest of the LU3 MGWAG profile did not correlate with the mean yearly AF. In fact, the Pearson's bivariate analysis and regression model failed to establish statistically significant correlation between variables, $\mathrm{AF}$ and LU3 MGWAGs.

Furthermore, regression analysis has shown a strong direct correlation between mean UPG and mean AF of the different pre-medical courses. This denotes that the better mean UPG (lower UPG value) paradoxically translate to a lower AF. Simply put, this implies that bright students who entered UP with impressive UPGs and probably would graduate with good GWA ironically obtain lower AF and lower chances of entering UPCM.

The significant and strong but inverse correlation with moderate size effect between mean UPCAT and mean AF of the different pre-medical courses indicates that those who obtain higher UPCAT scores would ironically end up getting a lower AF and lesser chances of admission to UPCM as lateral entrants. Pre-medical courses with higher UPCAT cut-off would be associated with lower AF.

The lack of a statistically significant correlation between mean HSWA and mean AF of different pre-medical course may be due to unstandardized HSWA. Being derived from a wide variety of secondary schools with different grading standards and scheme that were not standardized for measure of scholastic performance, the HSWA may not be accurate and reliable.

Overall, the information obtained by this study invalidates the utilization of the current $\mathrm{AF}$ in recalibrating GWA for the purpose of leveling the playing field in the selection process for admissions at UPCM. It is supposed to correctively recalculate GWA, however it has committed a gross oversight through a sweeping assumption that all high GWAs were mainly and exclusively due to grade inflation and overrated grades. Its defect lies on its failure to consider that high GWAs could simply be due to good academic performance of intrinsically smart students as what was shown by the study.

Not only does the AF prove to be invalid in "correctively" adjusting GWA to ensure fairness, but it also allows the admissions of those with low GWA with high AF. No wonder that in the last four years of its application, it was observed in the UPCM admissions profile, that the yearly average GWAs and average NMATs went down significantly and continually. Likewise, the annual admissions of students with high Latin honors (summa cum laude and magna cum laude) markedly dropped. ${ }^{26}$

The invalidity of this incumbent AF formula was shown by its inverse correlation with UPG, UPCAT and even HSWA, which measure of students' intrinsic intelligence. Its inverse relationship with NMAT, GWAG and LU3 MGWAG, both from pre-medical courses and campus unit level, further puts into question its validity. The invalidity of the AF boils down to the formula from which it is derived. The mean GWAs being placed in the denominator of the AF computation, led to the paradoxical inverse effect on students' GWA recalculation. Instead of treating GWAs as having a positive direct effect on the AF, the formula treats it as a negative inverse effect, thus resulting to the observed reductions of yearly average GWAs, NMATs and percentage of high Latin honors in the admissions profile.

A recent study has recommended other formulas for $\mathrm{AF}$ that do not treat GWA as a denominator (inverse correlation variable) and could establish better correlation with academic performance of the medical students. ${ }^{18}$ These recommended formulas could even adjust GWAs into better predictors of students' grades and class ranking in the medical college as well as their performance in the physician licensure examination. 


\section{CONCLUSION AND RECOMMENDATIONS}

The current formula for the adjustment factor is not valid one as it does not serve its purpose of ensuring fairness and equality in the selection process of the UPCM. As this formula is grounded on a faulty assumption and erroneous treatment of the historical GWAs, it resulted to a decline in the yearly mean GWAs, NMATs and students with high Latin honors.

The adoption of the AF tipped the balance towards the admissions of those with lower GWAs and disadvantaged those who have graduated from pre-med courses with high GWAs.

Thus, we recommend that the implementation of the AF be immediately held in abeyance until its validity issues are resolved. The AF must be reformulated and redesigned, based on sound and valid assumption that would realistically level the playing field. This rectification must be done with dispatch, as the admissions process is a continuous yearly undertaking.

The AF must preferably be grounded and derived from variables/data that are standardized, institutionalized and common to all pre-medical courses such as NMAT. The reformulated AF must also be predictive of students'academic performance in the College of Medicine. Furthermore, studies, regular review and continuing evaluation must be conducted to check on its validity and to determine whether it still serves its purpose. Constant fine tuning and recalibration of the AF must be continually carried out to maintain it as up to date and rational.

\section{Statement of Authorship}

The author contributed in the conceptualization, acquisition, processing and analysis, drafting and revision of manuscript and final approval of the version to be published.

\section{Author Disclosure}

The author declared no conflicts of interest.

\section{Funding Source}

This study was self-funded.

\section{REFERENCES}

1. New Admissions Policy: As amended. Decisions of the UP Board of Regents. 1324th meeting. UP Gazette. 2017 January; 46(1).

2. Guevara RC. Review of University of the Philippines, Diliman Freshmen Admission Committee: Final Report. College of Engineering. August 15, 2005. Unpublished.

3. Bachen R. Grade Inflation in UK Higher Education. Stud High Educ. 2017Sept; 42(8):1580-600.

4. Muller-Benedict V, Gaens T. A New Explanation for Grade Inflation the Long-Term Development of German University Grades. Eur J High Educ. 2020 Jan; 10(2):181-201.

5. Carter M. Grade Inflation in Higher Education: Is the End in Sight. [Internet]. 2016. [cited $2016 \mathrm{Jul}$. Available from: https://www.nas.org/ academic-questions/29/3/grade_inflation_in_higher_education_is_the_ end_in_sight

6. Crumbley D, Flinn R, Reichelt K. What is Ethical About Grade Inflation and Coursework Deflation. Journal of Academic Ethics. [Internet].2010 [cited $2010 \mathrm{Nov}$. Available from: https://d1wqtxts1xzle7.cloudfront. net/52392111/What_is_Ethical_About_Grade_Inflation_an201703306112-zbehah.pdf?1490919266=\&response-content.

7. Bailey M, Rosenthal J, Yoon A. Grades and incentives: assessing competing GPA measures and post-graduate outcomes. Stud High Educ. 2014 Dec; 41 (9):1548-62.

8. Rush B, Elmore R, Sanderson M. Grade Inflation in North American College of Veterinary Medicine: 1985-2006. J Vet Med Educ. 2011; 36(1):107-13.

9. Caulkins, J, Larkey, P, \& Wei J. Adjusting GPA to reflect course difficulty. Heinz College Research. Research showcase at Carnegie Mellon University. [Internet]. 1996 [cited 2018 Jun]. Available from: http:// repository.cmu.edu/heinzworks/42/.

10. Ferguson E. Factors Associated with Success in Medical School: Systematic Review of the Literature. BMJ. 2002; 324:952-7.

11. Mercer A, Puddey I. Admissions Selection Criteria Predictors of Outcomes in an Undergraduate Medical Course: A Prospective Study. Med Teach. 2011 Dec; 33(12): 997-1004.

12. Schmidt FL, Hunter JE. The Validity and Utility of Selection Methods in Personnel Psychology: Practical and Theoretical Implications of 85 years of Research Findings. Psychol Bull. 1998; 124(2): 262-74.

13. Johnson VE. Grade Inflation: A Crisis in College Education. 1st ed New York: Springer; 2003.

14. Didier T, Kreiter CD, Buri R, Solow C. Investigating the Utility of a GPA Institutional Adjustment Index. Advances in Health Sciences Education. Non-cognitive Skills and Factors in Educational Attainment. 1st ed. The Netherland. Sense Publisher. 2006 May;11(2) 145-53.

15. Catabijan C G, Canal JPA, Ignacio SD, Rivera A. Academic Performance Profile of Students of UP College of Medicine Lateral Entrants from Class 1990 to Class 2013. Philipp J Health Res Dev. 2016 June; 2(20): 1-12.

16. Young JW. Grade Adjustment Methods. Rev Educ Res. 1993 June; 63(2):151-65.

17. Catabijan CG, Ignacio SD, Canal JPA. Predictors of Academic Performance of Medical Students of UP College of Medicine. Philippine Journal of Health Research and Development. 2017 September; 3(21):64-72.

18. Catabijan CG, Ignacio SD, Canal JP, Ignacio KH, Jesus Emmanuel AD Sevilleja JE, Cruz MK. Comparison of the Different Adjustment Factors for Admissions to the UP College of Medicine. Philippine Journal of Health Research and Development. 2020 Jan; 24(1):1-7.

19. Linn RL. Grade Adjustments for Prediction of Academic Performance: A Review. J Educ Meas.1996 Jan; 3(1):1-29.

20. Barry DA, Seng S, Wardlaw RB, Crapper M, Smith SD. A Robust Grade Adjustment Procedure. Int J Eng Educ. 2004; 20(5):820-33.

21. Julian ER. Validity of the Medical College Admission Test for Predicting Medical School Performance. Acad Med. 2005 Oct; 80(10):910-7.

22. Scanlan J, Care D. Grade inflation: Should we be concerned? J Nurs Educ. 2004; 43(10):475-8.

23. Lackey L, Lackey W. Grade Inflation: Potential causes and solutions. Int. Journal of Engineering Education. 2006; 22(1):130-9.

24. Annual Admissions Reports: Admissions Office. University of the Philippines College of Medicine. Academic Year: 2013-2019.

25. Catabijan CG, Ignacio SD, Canal JP, Rivera A. Pre-admission Profile of the Medical Students of the University of the Philippines, College of Medicine: Class 1990 to Class 2013 Lateral Entrants. Philippine Journal of Health Research and Development. 2016 April; 2(20): 42-52.

26. Catabijan CG, Perez MM. The Initial Impact of the University of the Philippines College of Medicine New Admissions Policy: Four Years of Implementation. Philippine Journal of Health Research and Development. 2021 April; 2(25):40-54.

27. Mendoza AC. Office of Admissions, University of the Philippines, Memorandum No. ACM 2018-16. Re: UPCAT 2018 UPG Cut-off. May 3, 2018.

28. Raganit R. How to compute UPG from UPCAT[Internet]. 2020 [cited 2021 May]. Available from: Filiknow.net. https://filipiknow.net/how-tocompute-upcat-upg/. 